INVESTIGACIONES

de HISTORIA ECONÓMICA

2005, invierno, número 1. Pp. 81 a 96

\title{
Matemáticas, fiscalidad y crítica de la Escuela Clásica. El pensamiento liberal de José Alonso López
}

\section{Mathematics, Taxation and Criticism of Classical Political Economy. The Liberal Thought of José Alonso López}

\author{
FAUSTO DOPICO GUTIÉRREZ DEL ARROYO \\ Universidad de Santiago de Compostela
}

\begin{abstract}
RESUMEN
ABSTRACT

José Alonso López es una de las figuras más sugestivas del primer liberalismo español. En este artículo se analizan algunos de los rasgos más destacados de su pensamiento: la asociación entre liberalismo político y económico, la crítica a la abstracción económica desvinculada del análisis concreto, la utilización de métodos matemáticos avanzados y su singular propuesta de un impuesto sobre la renta con tipos progresivos.

PALABRAS CLAVE: pensamiento económico, liberalismo, economía matemática, José Alonso López.

Códigos JEL: B31, B41.

José Alonso López is among the most suggestive figures of the first Spanish liberalism. Some of the most outstanding features in his thought are the object of this article: the links between political and economic liberalism; his criticisms to economic abstractions detached from factual analysis; the use of advanced mathematical methods; and his singular proposition of an income tax with progressive rates.

KEY WORDS: Economic Thought, Liberalism, Mathematical Economics, José Alonso López.

JEL Codes: B31, B41.
\end{abstract}




\section{Ciencia, técnica y compromiso político. Síntesis biográfica de José Alonso López}

$\mathrm{J}$ osé Alonso López y Nobal es una de las figuras intelectualmente más atractivas del primer liberalismo español ${ }^{1}$. Nacido en Ferrol el 2 de diciembre de 1763, era marino de profesión, ingeniero, matemático y, según uno de sus principales biógrafos, Emiliano Balás, conocía siete idiomas y "tocaba con perfección instrumentos musicales hasta el mismo número"2 ${ }^{2}$ Fue profesor de Navegación en la Academia de Guardias Marinas de su ciudad natal, encontrándose al cargo de su observatorio astronómico cuando fue visitado, en 1799, por Alexander von Humboldt ${ }^{3}$. En 1803, fue nombrado Comisario de la Inspección General de Caminos de Galicia y, en 1808, Comandante de Ingenieros de las fortificaciones de la ría de Ferrol, cargos de los que fue suspendido con la invasión francesa. Representó a la provincia de Betanzos en la Junta Superior de Subsidios, Armamento y Defensa del Reino de Galicia, constituida en marzo de 1810, quien le encargó la gestión de la fábrica de fusiles de Xubia, en las cercanías de su ciudad natal.

El 30 de julio de 1810 es elegido por la Junta de Galicia como su representante en las Cortes de Cádiz, teniendo una activa participación en el desmantelamiento legislativo de las estructuras jurídicas del Antiguo Régimen y en la formulación de un nuevo marco político constitucional ${ }^{4}$. Sus intervenciones parlamentarias se relacionan con aspectos claves de la revolución liberal, participando muy activamente en las discusiones sobre la abolición de los señoríos, la propiedad de la tierra y la cuestión fiscal. Se ve obligado a exiliarse a Francia tras la vuelta de Fernando VII en 1814, es nuevamente diputado en la legislatura de 1820-21 y, posteriormente, segundo alcalde de su ciudad natal. Muere el 26 de diciembre de 1824, desolado ante la dramática conclusión del Trienio liberal ${ }^{5}$.

Su estancia en el exilio fue intelectualmente fructífera, pues allí escribió las Consideraciones generales sobre varios puntos históricos, politicos y económicos, a favor

1 Una primera versión de este artículo fue presentada en la III Reunión de la Asociación Ibérica de Historia del Pensamiento Económico (Granada, 2003). Los comentarios de Salvador Almenar, Ángel Fernández González, Alberto Lozano, Antonio Macías, Susana Martínez, Eduardo Pis, María Xosé Rodríguez Galdo y los evaluadores anónimos de IHE, han permitido mejorar considerablemente la redacción inicial. El curso impartido en diciembre de 2002 por Salvador Almenar en la Facultad de Ciencias Económicas y Empresariales de Santiago, sobre "Cuantificación y medición en la Historia del Análisis Económico: Un panorama (1650-1950)", constituyó asimismo un estímulo para retomar el pensamiento de Alonso López.

2 Balás (1888), pp. 159-160. Sobre la vida de J. Alonso López, véanse también Villa-Amil y Castro (1975 [1875]); Couceiro Freijomil (1951), tomo I; González Mariñas (1996) y De-Cal (1999).

3 Véase Fraga Vázquez (1999), pp. 68-69.

4 Véanse Dopico (1978) y De-Cal (1999).

5 Balás apunta que "sufrió persecuciones y murió delirando con sus perseguidores"; Balás (1888), p. 160. 
de la libertad y fomento de los pueblos, y noticias particulares de esta clase, relativas al Ferrol y a su comarca, que editó, gastando en ello su fortuna personal, en Madrid en 1820. La obra, aparecida de forma anónima, consta de seis tomos y un cuaderno de láminas, los cinco primeros impresos por M. Repullés y el sexto por Eusebio Álvarez. En las 1.680 páginas que componen el texto, el autor muestra una gran erudición, y trata con notable profundidad, para los conocimientos de la época, múltiples aspectos históricos, geográficos, biológicos, económicos y sociales, tanto de España y Galicia como, particularmente, de la comarca ferrolana.

En las páginas que siguen veremos algunos de los rasgos más sobresalientes del pensamiento de Alonso López. Su compromiso ideológico y vital con el liberalismo es compatible con la creencia de que la intervención del Estado puede facilitar el desarrollo de los intereses individuales. Pero, para ser eficaz, la acción pública debe basarse en el conocimiento de la realidad económica y social. Es aquí donde el análisis estadístico, demográfico y matemático adquiere una singular importancia. La utilización de este tipo de herramienta no le lleva, sin embargo, a una visión ahistórica o meramente cuantitativa. Antes bien, critica las explicaciones unicausales de los fenómenos sociales, e insiste en la interdependencia entre los factores jurídicos, políticos y económicos. Firme partidario de la ciencia, la tecnología y el análisis racional para impulsar el crecimiento económico y resolver los conflictos sociales, hasta el punto de comprometer su vida en la defensa de sus ideas, no cree, sin embargo, que la razón sea la única, ni quizá siquiera la superior, forma de conciencia. Son muy expresivas, a este respecto, sus consideraciones sobre la sensibilidad femenina:

“La mujer está algo deprimida en su ser, y es la mitad de la existencia humana. La debilidad de la constitución física de su sexo, no es una razón suficiente para robarla este derecho, porque sus facultades intelectuales son de la misma intensidad de fuerza que las del hombre, si se enrobustecen con la educación (...). Por más que el hombre se envanezca con una superioridad que él mismo se formó, la mujer lo humilla, porque la mujer le dio la luz del día, y conservó en su seno todo el compuesto de su existencia. Sus gracias, ya reales, o ya caprichos de la imaginación, prevarican al sabio, rinden a sus pies al guerrero intrépido, y hermosean la naturaleza sensitiva, sin cuyos encantos el mundo quedaría yermo, y hundido en un caos de lóbregas y tristes tinieblas"'6.

6 Alonso López (1820), t. I, pp. 59-60. En adelante, las referencias de citas textuales de esta obra aparecerán entre paréntesis en el texto. 


\title{
2. Política y economía en la crisis del Antiguo Régimen
}

La formación intelectual como ilustrado de Alonso López y su compromiso personal en la lucha contra el Absolutismo, actúan como el eje central en torno al que se desarrolla su pensamiento social. "La política es capaz de sacar partido de todas las inclinaciones humanas para gobernar y hacer felices los estados, pues que puede igualmente servirse para este fin de la razón y de las pasiones de los hombres, como de la ignorancia y de las luces" (t. VI, p. 10). A la ética de la felicidad pública propia del siglo XVIII, se suma la defensa apasionada del liberalismo político y económico, que se hallan claramente entrelazados. Si bien existen unos "principios de felicidad general porque todos los estados, todos los hombres, no forman sino un mismo pueblo, a los ojos de la naturaleza", los medios para conseguirla "deben ser dependientes de la situación, inclinaciones, producciones del país, y necesidades más urgentes, y todos los esfuerzos dirigidos a este fin, no pueden menos que ser relativos a estas diferentes circunstancias y afecciones" (t. III, p. 126).

Las causas de la crisis económica se hallan en la política de Fernando VII:

\begin{abstract}
"En breve tiempo se llenaron de gentes todas las prisiones del reino, se ensangrentaron con frecuencia los patíbulos, y se proscribieron familias enteras con el confisco de todos sus bienes, lo que originó un empobrecimiento lastimoso en todo el país, no tan solamente por los muchos capitalistas y hombres útiles que se expatriaron huyendo de los efectos de la persecución, sino también por la seguridad que daban estos procedimientos de que las Américas se separarían de los intereses de la España" (t. III, p. 26).
\end{abstract}

Alonso no se queda, sin embargo, en un mero análisis coyuntural, sino que cuestiona los fundamentos de la sociedad estamental y la economía propia del feudalismo desarrollado. En realidad, la política absolutista es negativa porque reproduce las estructuras económicas y sociales del Antiguo Régimen. Conforme profundiza en su análisis, se va encontrando con los obstáculos feudales al desarrollo económico. Con su supresión, la nobleza, "la clase que sin capitales propios se hace opulenta en España sobre el sudor y el capital ajeno" (t. III, p. 235), hegemónica debido a sus privilegios y no por su función social, cederá el paso a los capitalistas. Y Alonso propugna una revolución liberal en cuyo centro se halla la propiedad privada de la tierra - porque "donde no hay propiedad, no hay apego, y donde no hay apego hay facilidad al ocio, a la indiferencia" (t. III, p. 58)-, la desamortización y la privatización de los bienes comunales. El objetivo más deseable sería extender la pequeña propiedad, porque si cada cabeza de familia "poseyese aunque no fuera sino un palmo de terreno, el suelo estaría más cultivado, porque cada 
propietario procuraría de un modo o de otro beneficiar estas pequeñas porciones, y la generalidad de la nación resultaría más servida y arraigada en lo que pudiese ser" (t. III, pp. 58-59).

La observación del crecimiento económico en otros países convence a Alonso de que el desarrollo agrícola debe preceder al industrial. Es preciso "promover primero la agricultura a fin de que haya sobrantes" (t. I, p. 95). En cuanto a las manufacturas, constituyen "un preciso arbitrio para ocupar muchos brazos sobrantes a la Agricultura, y para atraer al país alguna riqueza extranjera, o para evitar que salga fuera la nacional; pero es preciso que este establecimiento sea muy posterior al fomento y progreso de la Agricultura, para dar lugar a que se consolide, y que ella misma manifieste los brazos que la sobran, y las producciones que puede prodigar a las artes, a fin de que no se extraigan caudales en comprar las primeras materias, en detrimento del agrícola nacional que puede franquear estas necesidades" (t. III, p. 73).

Para el desarrollo industrial, por su parte, es esencial la libertad de establecimiento y ejercicio, "pues limitar la industria de cualquier clase que sea con prohibiciones y privilegios exclusivos, es dañar no solamente al interés particular que se halla embargado en su acción, sino también al interés general de la sociedad, porque se la minoran los recursos a sus necesidades" (t. II, p. 171). La mejor fórmula consistiría, además, en una integración del sector transformador con el primario: "Mucha puede ser la felicidad de un Estado, en donde estas dos ocupaciones de la sociedad se auxilian mutuamente sin gravarse, presentando las artes un consumo vivificador a la agricultura, y esta una prodigalidad regulada a las artes, tanto en materias de su producción como en brazos sobrantes" (t. III, p. 75).

Si la agricultura es, en las condiciones de la España de su época, la base del crecimiento económico, el papel dinamizador de éste corresponde a la circulación de la riqueza: "Las riquezas paradas nada producen, así el movimiento de ellas da aumentos progresivos de un carácter cierto de realidad y de crédito; y en dos estados de una misma riqueza efectiva comparada en un tiempo determinado, aquel llegará a ser más rico que la haga circular más veces en un mismo tiempo" (t. I, p. 70).

Otorgar un papel importante al crecimiento agrario es usual en la Ilustración y el liberalismo español de la época. Ello no implica, sin embargo, la presunción de que sólo la agricultura crea producto neto. Antes bien, Alonso cree en la existencia de un proceso de valorización que se desarrolla a través de "diferentes y combinadas labores" del proceso productivo. De esta manera, los bienes crecen en "riqueza", de forma "que hay materia primera que después de haber pasado por todas las manipulaciones correspondientes a su estado final, rinde un beneficio en la razón de uno a cinco millones y medio respecto a los dos términos de materia en bruto y de obra concluida" (t. III, p. 75). 


\section{Crítica de las leyes económicas abstractas}

El precio final, sin embargo, no es el resultado ni del coste de producción, ni de la oferta y la demanda. Y es que el autor está en desacuerdo con las explicaciones unicausales, y con la existencia de leyes deterministas que rigen el funcionamiento del sistema económico. En su rechazo de aspectos esenciales de la economía clásica influyen, posiblemente, las dificultades de asimilación de un nuevo esquema conceptual y el dramático momento de transición en que se halla su país, pero también su manera de pensar, que le lleva a insistir una y otra vez en la multicausalidad e interdependencia de los acontecimientos sociales, y la importancia del contexto histórico en que estos se producen. Visión del mundo de la que su propia obra, en la que trata de hilvanar de forma coherente numerosas facetas de la realidad, es una buena muestra.

Esto es también aplicable al "precio de las cosas", que, en su opinión "es dependiente, sin contar con las causas físicas, de la combinación o separación de varias causas políticas y morales; y aún entre estas causas de una influencia directa y general, hay grados relativos más o menos eficaces en los diferentes países en que obran, según las circunstancias son más o menos favorables para que estas causas hagan una impresión más o menos intensa" (t. III, p. 115). Y es que la formación del precio es más compleja de lo que parece, pues "el efecto carestía, que por las primeras ideas simples de su causa, se presenta ser dependiente del consumo y escasez, se descubre ser un producente de muchas causas parciales reunidas". Y Alonso enumera entre ellas, además de "desgracias, ya accidentales, ya comunes", la presencia de "tres cadenas, cuyos eslabones se extienden a larga distancia": la "influencia que tienen las diferentes instituciones de la sociedad", la "acción reunida de los distintos agentes de la opinión y costumbres" y los "diversos obstáculos de localidad" (t. II, pp. 173-174).

La asociación entre las ideas económicas y la acción política, y la insistencia en la "combinación de agentes" se une a un apreciable escepticismo frente a las generalizaciones abstractas, un rasgo que se encontrará posteriormente desarrollado por la escuela histórica alemana. La necesidad de tener en cuenta las circunstancias concretas es permanente en Alonso López y fundamentará su crítica a Adam Smith:

\footnotetext{
“Este principio luminoso, y que puede ser de una aplicación muy extensa en política, ha sido poco considerado por los que escribieron de economía pública, y así sus aserciones se resienten muy a menudo de la falta de certeza que pudiera presentar una análisis escudriñadora y concluyente: el autor del ensayo sobre la riqueza de las naciones, se desentendió mucho de esta necesidad, y así las consecuencias que se derivan del conjunto de ideas abstractas que produjo aquel economista inglés, son o dudosas, o inadmisibles, o finalmente erradas, en medio de que los conceptos generales y exposición de hechos que presenta el señor Smith, son de la más juiciosa y apreciable doctrina económica" (t. II, p. 174).
} 


\section{Análisis estadístico y demográfico}

Para Alonso López, la acción política exige el conocimiento científico de las condiciones concretas. Esto le lleva a una preocupación constante por la estadística social, y a proponer la creación de Comisiones Estadísticas que, "bajo un plan bien estudiado y económico", estarían "repartidas a un mismo tiempo por todas las provincias de España" (t. III, p. 80).

Las cifras, los ejemplos numéricos y las tablas estadísticas inundan los diferentes capítulos de su obra, proporcionando innumerables datos sobre meteorología, astronomía, geología, biología..., y sobre la economía y sociedad de la época, en particular sobre la comarca de Ferrol, que estudia minuciosamente. La estadística se convierte en una forma de conocimiento que precede y posibilita la adopción de medidas políticas, económicas y militares. Y dentro de esta presencia abrumadora, sobresale el tratamiento que Alonso hace de los datos demográficos.

Alonso hereda en buena medida el sentimiento poblacionista mayoritario en la Ilustración española. Este poblacionismo, sin embargo, está matizado por la interdependencia entre los sectores económicos y su crítica de la población ociosa e improductiva: "sin población no hay brazos para la agricultura, y sin agricultura no hay vida, no hay existencia de población; sin industria ni comercio está amortiguada la agricultura, y muchos brazos sin ocupación y lánguidos" (t. III, p. 2). Aplicando estos principios a la decadencia de España, encuentra "dos causas generales íntimamente unidas las unas a las otras en sus modos de obrar, que son la despoblación del país, y el decremento de la agricultura". Pero esto se deriva de "otras dos causas radicales, que son la desproporción entre los miembros útiles y laboriosos del estado y los individuos improductivos y sin acción de fomento, y también la enorme desigualdad de rentas y riquezas entre las dos clases seglar y eclesiástica" (t. I, p. 99).

Fiel a la importancia que otorga al conocimiento cuantitativo, Alonso analiza los datos de los censos de la segunda mitad del siglo XVIII y la evolución de la población española en los quince primeros años del siglo XIX. Calcula una población de 10.885.000 habitantes en 1815 y realiza, tras una minuciosa discusión, una estimación de la posible tasa de crecimiento acumulativa a aplicar en el futuro. A partir de aquí, extrapola estos datos para todo el resto del siglo. Se trata de la primera proyección, y previsión, de la población española. Y, además, no resulta exageradamente desacertada. Pronostica trece millones y medio de habitantes para 1860 y casi dieciséis y medio para 1900, con un error absoluto en ambos casos de unos dos millones y unos errores relativos del 14 y el 12 por 100, respectivamente. Unos márgenes que, a tan largo plazo, no serían despreciados por ningún demógrafo actual.

Alonso se ocupa de la salud de los individuos y de los pueblos, que cree depende de "la reunión más o menos combinada de causas físicas y morales" (t. II, p. 84). Opina que la vida del hombre se encuentra abreviada con respecto a sus posibilida- 
des biológicas debido "a la ignorancia de los medios para prolongarla y por el abuso de la robustez y extravíos de las pasiones que tantas enfermedades engendran de todas especies" (t. II, p. 91). La relativa benignidad de la morbilidad y mortalidad de Galicia ${ }^{7}$ se debe fundamentalmente a la "bondad del clima", pues los naturales del país no son especialmente cuidadosos en lo que se refiere a una larga lista de factores, que van desde la dieta alimenticia y la poca "limpieza en personas y aposentos" hasta aspectos psicológicos, como "el carácter rencilloso que los anima, que después de consumirles su salud, les aniquila sus pequeñas fortunas en pleitos tenaces, en virtud de la jurisprudencia oscura, viciosa, y tan complicada con que se deciden las cuestiones" (t. II, p. 97).

En la prevención y mejora del tratamiento de las enfermedades, aparece de nuevo su gusto por la estadística: "No sería molesto ni extraño que los médicos y titulares de los pueblos a lo menos formasen una descripción de sanidad anual de sus respectivos territorios, fundada en las circunstancias meteorológicas observadas durante el curso del año, (...) los efectos que se notaron en la salud de los robustos, valetudinarios, niños y ancianos cuando los fríos eran intensos, los calores excesivos, las lluvias o nieves copiosas, la electricidad muy visible, etc." (t. II, p. 95). Y en un momento en que la publicación de los datos del movimiento de la población por una autoridad administrativa sólo se da en los países escandinavos ${ }^{8}$, pide la confección de "unos estados necrológicos en que se expresase por edades y clase de dolencias en número de muertos", y su publicación anual "por provincias o distritos por el gobierno" (t. II, p. 95).

Mientras todo esto no se puede llevar a cabo, el autor hace una notable contribución personal a partir de datos procedentes de la comarca de Ferrol, averiguados de "distintos modos, ya por caminos directos, y ya por senderos extraviados" (t. III, p. 44). Alonso agrupa los fallecidos por intervalos de edad, acumula las contribuciones de cada grupo y, finalmente, estima la serie de supervivientes ${ }^{9}$. A partir de aquí podríamos calcular la esperanza de vida y las restantes columnas que componen en la actualidad cualquier tabla de mortalidad. El problema no sólo reside en la discutible representatividad de los datos, sino también en que el método empleado sólo es adecuado para el caso de poblaciones cerradas y estacionarias, condiciones que, de acuerdo con las propias descripciones del autor, estaban lejos de cumplirse. A nivel de las técnicas demográficas existían ya procedimientos mejores, pues Wargentin, en el siglo anterior, había elaborado tablas a partir de los cocientes de mortalidad ${ }^{10}$, pero

7 La esperanza de vida de la población gallega en los siglos XVIII y XIX era claramente superior a la media española. Véanse Dopico (1987), Dopico y Rowland (1990) y Rodríguez Galdo (1993).

Dupâquier (1976).

Alonso López (1820), t. III, pp. 37 y ss.

Dupâquier (1977). 
no eran aplicables en este caso, pues no se disponía de una información fiable de la distribución por edades de la población. La falta de validez de los resultados no debe hacer olvidar el carácter pionero del escritor ferrolano al confeccionar la primera tabla de vida realizada en España.

\section{Una propuesta de impuesto progresivo sobre la renta}

La sustitución del sistema fiscal de Antiguo Régimen por un nuevo ordenamiento más sencillo y equitativo, y que facilitara el desarrollo económico, era una de las principales preocupaciones de Alonso López. Ya en las Cortes de Cádiz había tenido un destacado papel en las discusiones de las Comisiones de Hacienda, y sus intervenciones contribuyeron de forma significativa a la redacción del proyecto de julio de 1813, recogido por el Decreto de 13 de septiembre del mismo año ${ }^{11}$. Y aunque éste tuvo un escaso alcance práctico, debido a las dificultades para su aplicación y al retorno del Absolutismo, constituyó durante mucho tiempo una importante referencia doctrinal para el liberalismo español.

En el tomo III de las Consideraciones generales, el autor realiza una Historia del sistema de contribuciones en España, insistiendo en la "monstruosa complicación de impuestos y gravámenes" (t. III, pp. 223-224). Se detiene en el análisis del sistema de cupos implantado en 1817, donde "no se descubre ninguna regla de proporcionalidad contributiva" y se halla basado "en ideas mezquinas y mal combinadas, que no en reflexiones unidas de los más triviales axiomas de economía política, aunque es muy común en los tiempos presentes implorar sin concierto los principios de esta ciencia moderna para todo" (t. III, pp. 269-270). Como ya había hecho en las sesiones de las Cortes Generales y Extraordinarias de $1810-1813^{12}$, realiza una contundente crítica de las contribuciones indirectas. Sus propuestas se basan, por una parte, en la reforma del sistema recaudatorio y de la administración tributaria, para que "los cobros llegasen al tesoro público manejados por las menos manos posibles, y que refluyesen y se incorporasen cuanto antes en la circulación de la sociedad, a fin de que los ciudadanos volviesen a recoger los productos de unas cantidades que se habían desprendido" (t. III, p. 273). Y, por otra, en el establecimiento de una contribución "directa y única" en razón a las "rentas o productos" de los contribuyentes.

Alonso estudia hasta ocho supuestos para estimar las posibles cuotas impositivas. La solución preferida implica un sistema claramente progresivo. Este tipo de

11 Véase López Castellano (1999).

12 López Castellano (1999), p. CXXXV. 
tributación era objeto ya de discusión doctrinal e, incluso, de aplicación a figuras impositivas concretas ${ }^{13}$, pero en nuestro caso llama poderosamente la atención la meticulosidad analítica y el empleo del cálculo infinitesimal para encontrar la solución óptima. Sigamos el razonamiento del autor.

A un contribuyente de renta $p$, que paga de contribución una fracción $n$, le quedará una cantidad $p(1-n)$. Si los tipos de gravamen son "geométricamente proporcionales" a las rentas "que gocen los contribuyentes", a uno de renta $p^{\prime}$ se le aplicará una cuota $n^{\prime}=n \cdot \frac{p^{\prime}}{p}$.

Ahora bien, si no se pone un tope a esta progresividad, llegará un momento en que a un contribuyente de mayor renta le quedará una cantidad menor que a otro con menores ingresos brutos. Para solventar esta dificultad, el autor expresa la cantidad conservada (lo que hoy denominaríamos renta disponible) mediante la función

$$
p^{\prime}\left(1-n^{\prime}\right)=p^{\prime}\left(1-\frac{n}{p} p^{\prime}\right)=\frac{p^{\prime}}{p}\left(p-n p^{\prime}\right) .
$$

y la deriva con respecto a $p^{\prime}$, con el objetivo de igualar esta derivada a cero y calcular para qué tipo impositivo la función alcanza su máximo. Reproduciendo textualmente a Alonso López:

“Este término de renta que llamaremos $x$ que deje un remanente máximo, y la fracción de contribución que le corresponde que llamaremos $y$, será cuando $\frac{x}{p}(p-n x)$ tenga el mayor valor posible, lo que se verifica cuando es $\frac{p d x-2 n d x}{p}=0$ de donde sale $x=p / 2 n$, y por consiguiente la fracción de contribución $y=1 / 2$, o lo que es lo mismo 50 por 100 del producto o renta que se goce"14.

Finalmente, el autor acaba recomendando la adopción de una renta mínima a partir de la que se tributaría, un tipo de gravamen máximo no superior al 50 por 100, y una graduación de "las fracciones contributivas intermedias entre la máxima y la mínima" (t. III, p. 264).

3 Véase Seligman (1909).

14 Alonso López (1820), t. III, pp. 251-253. Este razonamiento puede expresarse asimismo de la siguiente forma: $x$ es una variable, la renta, que toma los valores $p, p^{\prime}, p^{\prime \prime}, p^{\prime \prime \prime}, \ldots \ldots$, e $y$ otra variable, el tipo de gravamen, que toma los valores $n, n^{\prime}, n^{\prime \prime}, n^{\prime \prime \prime}, \ldots \ldots$. La relación entre $x$ e $y$ es una constante. Sea esta $k$. Entonces $x=k y$. Para una renta $x$ la cantidad que resta tras pagar un impuesto con tipo $y$ será: $x(1-y)=k y(1-y)$. Dado que $k$ es una constante, maximizar esta expresión es equivalente a maximizar $Q=y(1-y)$. Derivando $Q$ respecto a $y$ e igualando a cero obtenemos: $\frac{\partial Q}{\partial y}=1-2 y=0$, de dónde $y=\frac{1}{2}$. 
El proyecto fiscal de Alonso presenta un indudable atractivo, ya que implícitamente satisface muchas de las condiciones que numerosos hacendistas suelen exigir a un sistema tributario. Los presupuestos anuales deben estar equilibrados, ya que los gastos "muy raras veces pueden exceder de los ingresos de sus contribuciones ordinarias"; y ser suficientes, pues, de acuerdo con la importancia que otorga a la gestión política y administrativa, deben "cubrir las atenciones comunes y permanentes del estado, como son los dispendios de la judicatura, de la fuerza armada y permanente, de los establecimientos de fomento nacional, y de la diplomacia y alto gobierno. Para la aplicación de estos fines ninguna carga es pesada ni ruinosa, cuando el todo de estas instituciones está en su debido arreglo (...) cuanto sobre ellas se funda la existencia y conservación de la sociedad, en la cual por los convenios tácitos sociales cada uno de los individuos que forman esta gran familia, reciben ventajas parciales emanadas de los beneficios generales, y logran de una precisa protección individual dimanada de la unión y fuerza universal" (t. III, p. 249). Y además, como hemos visto en su formulación de un impuesto único sobre la renta con tipos progresivos, tiene en cuenta la capacidad de pago del contribuyente, sirve de instrumento para la redistribución de la renta, y está abierto a la consideración de circunstancias personales, como la división en casados y solteros ${ }^{15}$. Una ambiciosa propuesta imposible de ser llevada a la práctica en el convulso período histórico en que le tocó vivir.

\section{A modo de conclusión: liberalismo, estadística y análisis matemático}

Dentro de la Historia del Pensamiento Económico podemos encontrar dos enfoques principales. Uno, el de la teoría económica, pretende explicar los hechos mediante la formulación de modelos analíticos abstractos. Otro, el de la economía aplicada, busca fundamentalmente desarrollar instrumentos y propuestas tendentes a estimular el crecimiento y el bienestar colectivo. Alonso López se encuentra claramente en el segundo grupo. Implicado personalmente en el esfuerzo legislativo para sustituir el entramado jurídico hasta entonces vigente por una sociedad de ciudadanos iguales ante la ley, es plenamente consciente de que el cambio económico y social no será posible sin el desmantelamiento del Antiguo Régimen.

Para construir una nación desde una perspectiva liberal había previamente que conocerla. Los pensadores económicos y sociales atraídos por la Revolución Francesa dieron un nuevo contenido a los desarrollos conceptuales e instrumentales

15 Alonso López (1820), t. III, p. 292. 
fraguados en la aritmética política inglesa y la estadística descriptiva alemana ${ }^{16}$. Poseedor de una excelente formación técnica e incansable usuario de todo tipo de estadísticas ${ }^{17}$, Alonso propuso la creación de una serie de registros públicos, especialmente en el ámbito demográfico y sanitario, que iban en esta dirección. La estadística posibilitaba el conocimiento científico de la realidad y, por consiguiente, facilitaba la adopción de decisiones tanto por los agentes individuales como por los poderes públicos.

Las preocupaciones de Alonso López en este aspecto son similares a las de su coetáneo Juan López de Peñalver, cuya relevancia en la Historia del Pensamiento Económico español ha quedado resaltada tras la edición de sus escritos por Ernest Lluch. Con él comparte, junto al empleo de un rico instrumental matemático, el gusto por la historia y la crítica al excesivo carácter especulativo de las ideas económicas de Adam Smith ${ }^{18}$.

Los que podemos llamar aritméticos políticos de la época no solían acudir a una herramienta tan sofisticada como el cálculo diferencial. El desarrollo del análisis infinitesimal por parte de Isaac Newton y Gottfried Wilhelm Leibniz en la segunda mitad del siglo XVII, representó el surgimiento de una nueva forma de pensar en la historia de la ciencia: la descomposición de un todo en infinitas partes indivisibles y la recomposición del todo mediante la agregación de dichas partes ${ }^{19}$. Difícilmente entendible por los mismos matemáticos de la época ${ }^{20}$, pasó a ser un utensilio esencial en el siglo siguiente, sobre todo a partir de la publicación, en 1748, de la Introductio in analysis infinitorum, donde Leonhard Euler integraba las ideas básicas y la notación de Leibniz y el método de las fluxiones, o velocidad de los cambios, de New$\operatorname{ton}^{21}$. El cálculo diferencial e integral, posibilitaba, entre sus muchas aplicaciones, la descripción de las trayectorias de los cuerpos en movimiento mediante ecuaciones diferenciales, y la explicación en estos términos del funcionamiento del sistema solar.

La intuición de Newton le había llevado a postular que la fuerza que movía los planetas alrededor del sol era la misma que la que provocaba la caída de la manzana. Para Newton, como todavía para los científicos actuales ${ }^{22}$, esta fuerza era, en último

17 De él conservamos, por ejemplo, los primeros datos meteorológicos de que se tienen noticia en Galicia. Véase Díaz Fierros (1976), p. 444.

18 Véanse el estudio preliminar de Ernest Lluch a la edición de los escritos de López de Peñalver (1992), especialmente sus consideraciones sobre las Reflexiones sobre la variación del precio del trigo (1812); así como los comentarios de Almenar (2000) y Lluch (2000).

19 Véanse Leibniz (1994a [1684]) y el estudio preliminar incluido de Javier de Lorenzo.

20 Leibniz (1994b [1686]), p. 17; y Boyer (1986), p. 501.

21 Boyer (1986), pp. 557-558.

22 Es muy probable que una partícula, conocida como gravitón, vehiculice la fuerza de gravedad, pero su existencia no ha podido ser comprobada experimentalmente. Véase Lederman y Teresi (1996), pp. 96-97. 
término, un misterio: "No he podido todavía deducir a partir de los fenómenos la razón de estas propiedades de la gravedad y yo no imagino hipótesis" ${ }^{23}$. Sus ideas, sin embargo, permitían describir la ley de gravitación universal como la mano invisi$b l e^{24}$ responsable del equilibrio planetario y del orden que configuraba el Universo, y se convirtieron en el fundamento de una representación del mundo físico que prevalecería hasta comienzos del siglo XX.

Los trabajos de Galileo, Descartes, Kepler, Newton y Leibniz permitían desvincular las explicaciones sobre el funcionamiento del mundo de las convicciones religiosas, y se constituyeron en uno de los soportes centrales de la gran renovación ideológica del siglo XVIII, donde son ya muchos los hombres cultos que creen en la existencia de un orden natural regulado por leyes objetivas. Alonso hereda esta creencia de la ciencia ilustrada y se refiere a la necesidad de un "dialecto científico" para que los hombres puedan entender "los maravillosos secretos y leyes de la naturaleza con peso y medida"; al mismo tiempo que alaba "el más sublime y extraordinario cálculo" empleado por Newton "para medir y pesar toda la materia que compone el universo" (t. III, pp. 186-187).

Muchos ilustrados también supusieron que, sustituidas las tinieblas de la ignorancia por la luces de la razón, sería posible encontrar unas leyes semejantes en el campo de las conductas humanas y los hechos sociales. Adam Smith creyó encontrar en el mercado un principio de organización similar en el terreno económico, y su fuerza motriz en la búsqueda del beneficio. La idea de una mano invisible que transformaba el deseo de lucro en virtud pública, constituyéndose en motor del crecimiento económico, era particularmente oportuna, porque satisfacía las ansias de enriquecimiento y ascenso social de la burguesía y otras capas intermedias, y contribuía a acallar los posibles escrúpulos morales y religiosos. José Alonso López, por su parte, piensa que es posible compatibilizar un pensamiento nítidamente liberal con el análisis de las "causas morales" (t. II, p. 84 y ss.), presentes tanto en el desarrollo de los hombres individuales como de los pueblos, y se resiste a esta simplista solución del problema de articular los intereses personales y los valores colectivos.

La escuela clásica, sin embargo, no hizo uso de los nuevos instrumentos matemáticos. La creencia en la existencia de unas leyes deterministas en los comportamientos económicos era relativamente fácil de aceptar en el contexto ideológico y científico de la época, pero su representación matemática era mucho más difícil, no sólo por la complejidad del análisis infinitesimal, sino también por la considerable audacia intelectual que suponía pasar de utilizarlo para calcular superficies y analizar la dinámica de los cuerpos o las mareas, a explicar el comportamiento

23 Newton (2003 [1687]), p. 1.019.

24 Greene (2001), p. 72. 
de consumidores y empresarios. Los clásicos, además, centraban su interés en el desarrollo de una teoría objetiva del valor basada en el valor trabajo, por lo que no prestaron atención a las posibilidades que el cálculo diferencial abría para el desarrollo de conceptos asociados a la utilidad de los bienes, como ya había vislumbrado Daniel Bernouilli en $1738^{25}$.

Antes de que el análisis infinitesimal se convirtiera en un instrumento conceptual y metodológico fundamental en el desarrollo de la teoría económica neoclásica, varios autores lo utilizaron para la resolución de problemas concretos de economía aplicada. Este es el caso de la temprana aportación de José Alonso López, que, sin duda, merece al menos una mención en la Historia del Pensamiento Económico.

\section{Bibliografía}

ALMENAR, Salvador (2000): “El desarrollo del pensamiento económico clásico en España", en FUENTES QUINTANA, Enrique, dir., Economía y economistas españoles. La economía clásica, IV, Barcelona, Círculo de Lectores-Galaxia Gutemberg, pp. 7-92.

ALONSO LÓPEZ, José (1820): Consideraciones generales sobre varios puntos históricos, políticos y económicos, a favor de la libertad y fomento de los pueblos, y noticias particulares de esta clase, relativas al Ferrol y a su comarca, Madrid.

BALÁS, Emiliano (1888): “Carta I sobre la obra del Sr. D. Alonso López de Nobal y su biografía”, en Galicia Diplomática, t. III, pp. 159-161.

BERNOUILLI, Daniel (1968 [1738]): "Exposition of a New Theory of Risk Evaluation", en BAUMOL, William J. y GOLDFELD, Stephen M., Precursors in Mathematical Economics: An Anthology, Londres, The London School of Economics and Political Science, pp. 15-26.

BOYER, Carl B. (1986): Historia de la matemática, Madrid, Alianza Editorial.

COUCEIRO FREIJOMIL, Antonio (1951): Diccionario bio-bibliográfico de escritores, Santiago, Bibliófilos Gallegos.

DE-CAL Y CORTINA, Rosa M. G. (1999): Memoria parlamentaria de D. José Alonso López. A súa contribución a formación do Estado liberal, Ferrol, Ateneo Ferrolán.

DESROSIÈRES, Alain (2000): La politique des grands nombres. Histoire de la raison statistique, Paris, La Découverte.

DÍAZ FIERROS VIQUEIRA, Francisco (1976): “La cultura científica”, en VV. AA., Los gallegos, Madrid, Istmo, pp. 432-456.

25 Véase Bernouilli (1968 [1738]). 
DOPICO, Fausto (1978): “José Alonso López, liberal e crítico das institucións do Antigo Réxime", Grial, 61, pp. 257-266.

-(1987): "Regional Mortality Tables for Spain in the 1860s", Historical Methods, Año 20, 4, pp. 173-179.

DOPICO, Fausto y ROWLAND, Robert (1990): “Demografía del censo de Floridablanca. Una aproximación", Revista de Historia Económica, Año VIII, 2, pp. 591618.

DUPÂQUIER, Michel (1976): “Quelques étapes dans le développement des publications démographiques nationales au XIXe siècle", en BÉDARIDA, François, et. al., Pour une histoire de la statatistique, París, Institut National de la Statistique et des Études Économiques, pp. 111-124.

—(1977): "Les tables de mortalité de Wargentin", Annales de Démographie Historique, 32, pp. 385-420.

FRAGA VÁZQUEZ, Xosé Antón (1999): “As cartas de Humboldt e a viaxe ás rexións equinocciais", en DÍAZ FIERROS VIQUEIRA, Francisco y ROZADOS GRELA Daniel, coords., Un novo mundo para un home universal. Partida de Humboldt desde A Coruña cara á súa viaxe americana, Santiago, Consello da Cultura Galega, pp. 6574.

GONZÁLEZ MARIÑAS, Pablo (1996): "Alonso López y el Ferrol de su tiempo", Ferrol. Análisis, 10, pp. 6-11.

GREENE, Brian. (2001): El universo elegante. Supercuerdas, dimensiones ocultas y la búsqueda de una teoría final, Barcelona, Crítica/Planeta.

LEDERMAN, Leon y TERESI, Dick (1996): La partícula divina. Si el universo es la respuesta, ¿cuál es la pregunta?, Barcelona, Crítica.

LEIBNIZ, Gottfried Wilhelm (1994a [1684]): “Un nuevo método para los máximos y mínimos, así como para las tangentes, que no se detiene ante las cantidades fraccionarias o irracionales, y es un singular género de cálculo para estos problemas", en DE LORENZO, J. (ed.), Análisis infinitesimal, Madrid, Tecnos, pp. 3-15.

LEIBNIZ, Gottfried Wilhelm (1994b [1686]): "Sobre una geometría altamente oculta y el análisis de los indivisibles e infinitos", en DE LORENZO, J. (ed.), Análisis infinitesimal, Madrid, Tecnos, pp. 17-29.

LÓPEZ CASTELLANO, Fernando (1999): “La contribución directa en las Cortes de Cádiz. Ideas, análisis económico y realizaciones", en MARTINEZ DE MONTAOS, Román, et al., El pensamiento hacendístico liberal en las Cortes de Cádiz, Madrid, Instituto de Estudios Fiscales, pp. IX-CCIV.

LÓPEZ DE PEÑALVER, Juan (1992): Escritos de _, edición y estudio preliminar de LLUCH, Ernest, Madrid, Instituto de Estudios Fiscales.

LLUCH, Ernest (2000): "Juan López de Peñalver. Un economista clásico", en FUENTES QUINTANA, Enrique (dir.), Economía y economistas españoles. La economía clásica, IV, Barcelona, Círculo de Lectores-Galaxia Gutemberg, pp. 441-446. 
MARTIN, Thierry (2003): Arithmétique politique dans la France du XVIIIe siècle, Paris, INED.

NEWTON, Isaac (2003 [1687]): Principios matemáticos de la filosofía natural, en HAWKING, Stephen (ed.), A hombros de gigantes. Las grandes obras de la Física y la Astronomía, Barcelona, Crítica, pp. 650-1020.

RODRÍGUEZ GALDO, María Xosé (1993): Galicia, país de emigración, Gijón, Archivo de Indianos.

SELIGMAN, Edwin R. A. (1909): L'Impôt progressif en théorie et en pratique, París, V. Griard y E. Brière.

VILLA-AMIL Y CASTRO, José (1975 [1875]): Ensayo de un catálogo sistemático y crítico de algunos libros, folletos y papeles así impresos como manuscritos que tratan en particular de Galicia, Barcelona, El Albir. 